\title{
Differenzierter Selbstbehalt bei Originalpräparaten und Generika
}

Gert Printzen" ${ }^{a}$ Ernst Gähler ${ }^{b}$

a Dr. med., Mitglied des Zentralvorstandes, Verantwortlicher Ressort Heilmittel

b Dr. med., Vizepräsident der FMH, Verantwortlicher Ressort Tarife und Verträge
Bisher galten ein Selbstbehalt von 10 Prozent für Generika und ein Selbstbehalt von 20 Prozent für Originale, zu denen es günstigere Generika gab. Seit dem 1. Juli 2011 kann auch ein Generikum neu einen Selbstbehalt von 10 oder 20 Prozent haben. Es gilt: «Für Arzneimittel, deren Höchstpreis den Durchschnitt der Höchstpreise des günstigsten Drittels aller Arzneimittel mit gleicher Wirkstoffzusammensetzung auf der Spezialitätenliste um mindestens 20 Prozent übersteigt, beträgt der Selbstbehalt 20 Prozent der die Franchise übersteigenden Kosten.» Die Generikaliste mit differenziertem Selbstbehalt bei Originalpräparaten und Generika wird monatlich durch das Bundesamt für Gesundheit aktualisiert. Diese Liste finden Sie unter www.bag.admin.ch $\rightarrow$ Themen $\rightarrow$ Krankenversicherung $\rightarrow$ Tarife und Preise $\rightarrow$ Spezialitätenliste $\rightarrow$ Index der SL-Verzeichnisse.

Die neue Regelung erschwert die Situation sowohl für Ärzte als auch für Patienten; es ist nicht voraussehbar, welche Medikamente künftig einen höheren Selbstbehalt nach sich ziehen werden, so dass man die Patienten möglichst nicht auf sie einstellen sollte.

Störend an solchen Regelungen ist erstens, dass ein Originalmedikament und sein Generikum verschiedene Wirkungen auslösen können: Denn auch wenn in beiden Arzneien der gleiche Wirkstoff steckt, unterscheiden sich Originalmedikamente und Gene- rika in ihrer Gesamtzusammensetzung; das Generikum ist keine Kopie des Originals. Gut bekannt ist das Problem beispielsweise bei den Medikamenten für Epileptiker.

Die auf die Bedürfnisse des einzelnen Patienten zugeschnittene optimale Arzneimitteltherapie wird durch diese neue Verordnung verunmöglicht. Er bedeutet eine massive Einschränkung der therapeutischen Freiheit und ist ein Eingriff in das Vertrauensverhältnis Arzt-Patient. Jeder Wechsel ist sowohl für den Patienten als auch den Arzt ein Risiko. Wir wissen, dass Galenik, Applikationsart, Pillengrösse und Pillenfarbe ebenso wichtig sind wie die Ökonomie des reinen Wirkstoffes. Das häufige Wechseln von Medikamenten gefährdet gerade bei polymorbiden Patienten, die etwa 80 Prozent der Kosten generieren, die Patienten-Sicherheit gravierend.

Neben den rein medizinischen Bedenken muss aber auch die «Alltagstauglichkeit» («Praxistauglichkeit») einer solchen komplizierten Verordnung, die ja Kosten sparen soll, massiv in Frage gestellt werden. Wie stellt man sich die Umsetzung konkret vor? Der administrative Aufwand wächst immens!

Die Politik betreibt paradoxe Kommunikation, wenn sie den Ärzten und Patienten solche Regelungen (zudem noch ohne vorgängiges Anhörungsverfahren) aufzwingt und gleichzeitig möchte, dass die Ärzte sich noch intensiver in der Medikamentensicherheit engagieren.

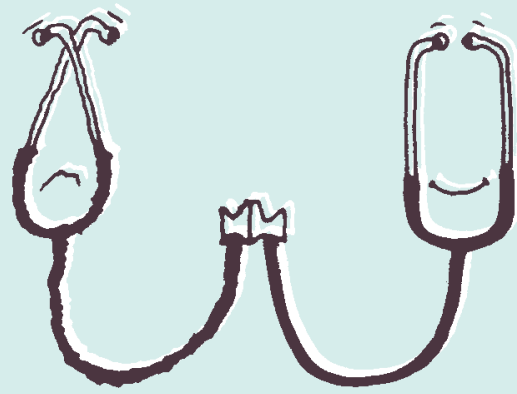

\section{Plötzlich selbst betroffen. Krisen treffen auch Ärztinnen und Ärzte.}

Lassen Sie sich helfen. Kontaktieren Sie ReMed.

24-Stunden-Hotline

$0800073633 \quad$ help@swiss-remed.ch

08000 ReMed www.swiss-remed.ch 